\title{
High-Efficiency Hydrolysis of Thermosetting Polyester Resins into Porous Functional Materials using Low Boiling Aqueous Solvents
}

Xiong-Lei Wang, ${ }^{\dagger}$ Wen-Li An, ${ }^{\dagger}$ Fei Tian, ${ }^{\dagger}$ Yang Yang, ${ }^{\dagger}$ Xu Zhao, ${ }^{\dagger}$ Ping-Ping Xu, ${ }^{\dagger}$ Shimei $\mathrm{Xu},{ }^{*}, \dagger$ and Yu-Zhong Wang*,†

$\dagger$ School of Chemical Engineering, Collaborative Innovation Center for Eco-Friendly and Fire-Safety Polymeric Materials (MoE), State Key Laboratory of Polymer

Materials Engineering, National Engineering Laboratory of Eco-Friendly Polymeric Materials (Sichuan), Sichuan University, No.29 Wangjiang Road, Chengdu 610064, China

\section{Corresponding authors}

*,† Shimei Xu: xushimei@scu.edu.cn

*,† Yu-Zhong Wang: yzwang@scu.edu.cn

Supporting Information consists of 4 pages, including this one.

There are 1 Tables and 2 Figures. 


\section{Materials properties}

Dichloromethane $\left(\mathrm{CH}_{2} \mathrm{Cl}_{2}\right.$, density: $1.33 \mathrm{~g} / \mathrm{cm}^{3}$, boiling point: $\left.39.8^{\circ} \mathrm{C}\right)$, potassium hydroxide $\left(\mathrm{KOH}\right.$, density: $2.04 \mathrm{~g} / \mathrm{cm}^{3}$, well soluble in water and soluble in ethanol), ethanol (EtOH, density: $0.79 \mathrm{~g} / \mathrm{cm}^{3}$, boiling point: $78^{\circ} \mathrm{C}$, soluble in water and most organic solvents), n-propyl butyrate (n-PB, density: $0.87 \mathrm{~g} / \mathrm{cm}^{3}$, boiling point: $142.7^{\circ} \mathrm{C}$, soluble in ethanol and slightly soluble in water), dipropyl phthalate (DP, density: $1.07 \mathrm{~g} / \mathrm{cm}^{3}$, boiling point: $317.5^{\circ} \mathrm{C}$, soluble in ethanol and insoluble in water), and ethylene glycol (EG, density: $1.11 \mathrm{~g} / \mathrm{cm}^{3}$, boiling point: $197.3^{\circ} \mathrm{C}$, soluble in in water) were purchased from Tianjin Zhiyuan Chemical Reagent Co., Ltd. (China). All the materials were used without purification.

\section{Design of experiment}

First, TUPR was pretreated by immersing into $\mathrm{CH}_{2} \mathrm{Cl}_{2}$ for $12 \mathrm{~h}$ to obtain the pretreated TUPR (PTUPR, 40-60 mesh), the $\mathrm{CH}_{2} \mathrm{Cl}_{2}$ was recycled and reused by filtration with the PTUPR. Then, the PTUPR was hydrolyzed at under different conditions mainly including solvent ratio, reaction temperature and reaction time. After reaction, the solid products were washed with EtOH to remove the residual reaction solution and dried at $80^{\circ} \mathrm{C}$. The reaction solution was recycled for the degradation of TUPR by repeating the above process. The characterization techniques of the products are shown in Table S1 and the design process of experiment is shown in Figure S1.

\section{Hydrolysis mechanism}


The hydrolytic cleavage of ester bonds in TUPR was proved by on-line FT-IR and GCMS-QP2010 Plus. Dipropyl phthalate and n-propyl butyrate were selected as model compounds. The hydrolysis reaction of model compounds in the $\mathrm{EtOH}-\mathrm{H}_{2} \mathrm{O}$ binary solution $(\mathrm{v} / \mathrm{v}, 9 / 1)$ with $\mathrm{KOH}$ as catalyst. The reaction progress were constantly monitored by on-line FT-IR and the reaction products were detected after acidizing with hydrochloric acid.

Table S1 characterization techniques of the product

\begin{tabular}{cc}
\hline $\begin{array}{c}\text { characterization } \\
\text { technology }\end{array}$ & Purpose of characterization \\
SEM & Morphology of the products \\
FT-IR & Chemical structure of the \\
products & Chemical structure of the \\
NMR & products \\
On-line FT-IR & Reaction process \\
GC-MS & Reaction products of model \\
compounds
\end{tabular}




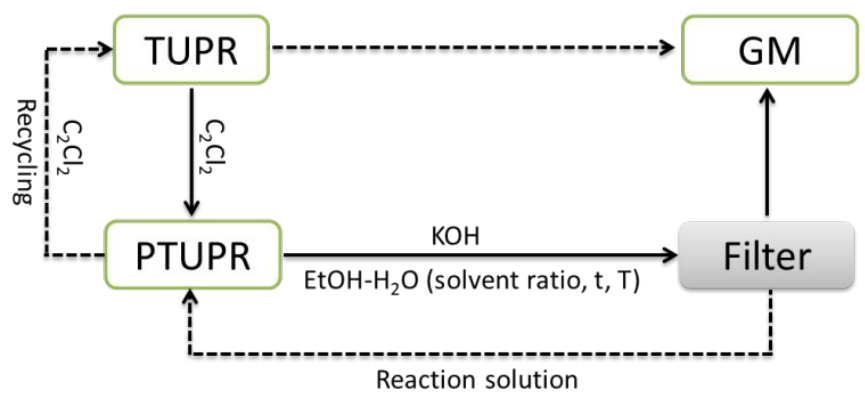

Figure $\mathrm{S} 1$ the design process of experiment

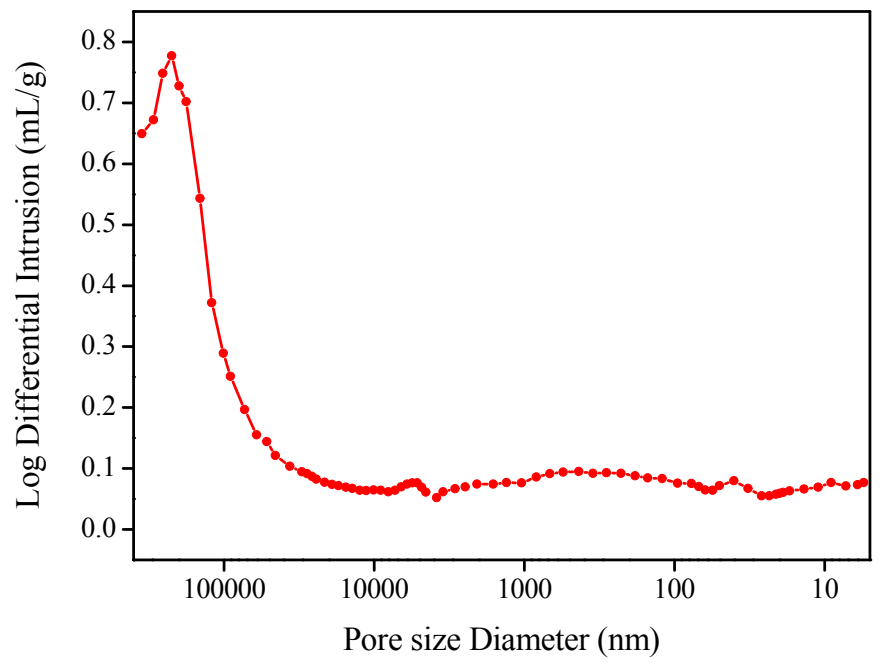

Figure S2 The log differential intrusion of the degradation product after reaction time of $30 \mathrm{~min}$ as a function of the pore size 